\title{
Epidemiology and treatment of Behçet's disease in the USA: insights from the Rheumatology Informatics System for Effectiveness (RISE) Registry with a comparison with other published cohorts from endemic regions
}

Nevin Hammam¹, Jing Li ${ }^{1}$, Michael Evans ${ }^{1}$, Julia L. Kay ${ }^{1}$, Zara Izadi ${ }^{1}$, Christine Anastasiou', Milena A. Gianfrancesco ${ }^{1}$, Jinoos Yazdany ${ }^{1}$ and Gabriela Schmajuk ${ }^{1,2,3^{*}}$ (D)

\begin{abstract}
Background: Behçet's disease (BD), a chronic systemic vasculitis, has distinct geographical and ethnic variation. Data regarding the epidemiology of patients with BD in the U.S. are limited; therefore, we sought to describe BD patient characteristics and medication use in the U.S., and compared them with data from patients from endemic regions.
\end{abstract}

Methods: We conducted a cross-sectional study using data from the RISE registry (2014-2018). Patients aged $\geq 18$ years with BD were included. Sociodemographic and treatment information was extracted. We compared patients from the RISE registry to data from other published studies of patients with BD from endemic areas.

Results: One thousand three hundred twenty-three subjects with BD from the RISE registry were included. Mean age was $48.7 \pm 16.3$ years, female to male ratio was $3.8: 1$, and $66.7 \%$ were White. The most frequently used medications included glucocorticoids (67.6\%) and colchicine (55.0\%). Infliximab and adalimumab were the most used biologics (14.5\% and $14.1 \%$, respectively); $3.2 \%$ of patients used apremilast. The RISE registry had more women (79.3\%), and patients were older compared to previously published BD studies from endemic areas. Methotrexate and TNFi were more commonly reported in RISE (21.8\% and 29.4\%) compared to studies from Egypt and Turkey. Colchicine, cyclosporine, and cyclophosphamide were more commonly used in cohorts from Egypt, Turkey, and Iran.

\footnotetext{
* Correspondence: gabriela.schmajuk@ucsf.edu

'Division of Rheumatology, Department of Medicine, University of California

San Francisco, San Francisco, CA, USA

${ }^{2}$ Philip R. Lee Institute for Health Policy Research, San Francisco, USA

Full list of author information is available at the end of the article
}

(c) The Author(s). 2021 Open Access This article is licensed under a Creative Commons Attribution 4.0 International License, which permits use, sharing, adaptation, distribution and reproduction in any medium or format, as long as you give appropriate credit to the original author(s) and the source, provide a link to the Creative Commons licence, and indicate if changes were made. The images or other third party material in this article are included in the article's Creative Commons licence, unless indicated otherwise in a credit line to the material. If material is not included in the article's Creative Commons licence and your intended use is not permitted by statutory regulation or exceeds the permitted use, you will need to obtain permission directly from the copyright holder. To view a copy of this licence, visit http://creativecommons.org/licenses/by/4.0/ The Creative Commons Public Domain Dedication waiver (http://creativecommons.org/publicdomain/zero/1.0/) applies to the data made available in this article, unless otherwise stated in a credit line to the data. 
Conclusions: Findings from the largest BD dataset in the U.S. suggest that BD patients are predominantly female. Further research is needed to explore the reasons for the higher prevalence of BD among women in the U.S. and its possible impact on disease severity and management.

Keywords: Behçet's disease, RISE, ECR, Endemic regions, Medication

\section{Background}

Behçet's disease (BD) is a chronic multisystem vasculitis that can increase morbidity and mortality. The prevalence of the disease, the frequency of specific clinical findings, and the mortality rate have distinct geographical and ethnic variation: $\mathrm{BD}$ prevalence is higher in the Middle East and East Asia but remains rare in North America [1]. In the United States (U.S.), the estimated prevalence ranges from 0.33 to 5.2 people per 100,000 population [2]. A male predominance with a severe disease course has been observed in Arab populations [3], while female predominance has been reported in 2 small studies of patients in the U.S. [4, 5].

The prevalence of BD in the U.S. is increasing, which may be due to increased disease recognition and immigration from endemic areas [2]; however, robust epidemiologic data about BD in the U.S. is scarce. While descriptive cohort studies of $\mathrm{BD}$ in the U.S. exist, they are from single centers, limited by small sample sizes, and have not reported data from multiple racial or ethnic groups [2, 4-6]. Furthermore, previous studies comparing the characteristics of patients with BD from the northeastern U.S. with patients from Turkey [5] and Iran [7] raised the possibility that BD in U.S. patients may have unique features compared to typical BD populations. However, to date, no national studies of BD in the U.S. have been published.

To better investigate the demographic characteristics, comorbidities, and medical treatment patterns of BD in the U.S., we used data from the Rheumatology Informatics System for Effectiveness (RISE). RISE is a national electronic health record (EHR) registry that captures all patients seen by participating U.S. rheumatologists [8] We also compared the available RISE-BD data with published epidemiological studies of BD from endemic regions.

\section{Materials and methods}

\section{Data source, timelines, and study population}

This observational study was conducted using data from the RISE Registry (2014-2018). RISE, a national electronic health record (EHR)-enabled rheumatology registry, collects data on all patients seen during routine outpatient clinical care in participating rheumatology practices across the U.S., reducing the selection bias present in single insurer-based studies [8]. As of 2018, RISE held validated data from 1113 providers in 226 practices, representing more than $30 \%$ of the U.S. clinical rheumatology workforce. Available data is collected through the EHR and includes individual demographics, diagnoses, procedures, medications, laboratory test results, and vital signs. Patients in RISE aged 18 years and older with at least 2 diagnosis codes (International Classification of Diseases, Ninth Revision, Clinical Modification (ICD-9-CM) 136.1 or ICD-10-CM M35.2) for BD at least $\geq 30$ days apart at any time during the study period were included [9].

\section{Covariates}

We extracted information on patient characteristics from the RISE registry. Patient characteristics included age, gender, race/ethnicity (White, Hispanic/Latino, Black/African American/other), geographic region of residence (East North Central, West North Central, Mid-Atlantic, Mountain, New England, Pacific, South Atlantic, East South Central, and West South Central), insurance type (private, Medicare, any Medicaid, other) when available, and the number of rheumatology visits during the study period. We examined clinical comorbid conditions, including a diagnosis of diabetes, asthma, hypertension, and osteoporosis. We also calculated the Deyo-Charlson Comorbidity Index (CCI) score using data recorded at any time during the study period [10].

\section{Medications}

Medications potentially related to $\mathrm{BD}$ were identified by either Generic Product Identifier codes or National Drug Codes. The following categories were identified (1) conventional synthetic DMARDs (csDMARDs): methotrexate, azathioprine, hydroxychloroquine, leflunomide, sulfasalazine, mycophenolate mofetil, cyclophosphamide, cyclosporine, minocycline, and tacrolimus; (2) tumor necrosis factor (TNF) inhibitors: etanercept, infliximab, adalimumab, golimumab, and certolizumab; (3) nonTNF biologics: abatacept, rituximab, secukinumab, ustekinumab, omalizumab, anakinra, canakinumab, tocilizumab, and sarilumab; (4) targeted synthetic DMARDs (tsDMARDs): tofacitinib, baricitinib, and apremilast; (5) systemic glucocorticoids including prednisone and other oral and intravenous steroids; and (6) anticoagulants including warfarin, rivaroxaban, apixaban, enoxaparin, dabigatran, and edoxaban. 


\section{BD studies from endemic regions}

We also reviewed the published studies to identify reports of BD from endemic regions. We searched PubMed for studies of "Behçet's disease" from 2010 to present (2020). Studies were eligible if they (1) reported on adults with BD; (2) were published in English; (3) included countries along the ancient Silk Road, extending from Japan to the Middle East, or Mediterranean countries including Turkey and Iran; (4) reported on $\geq 100$ BD patients; and (5) had information on demographic factors and medication use. In studies that included only specific BD phenotypes (uveitis, or neuropsychiatric BD) or that included patients younger than 18 years, we excluded these studies. For each included study, we abstracted the following data: number of patients, country, patients' age and gender, and related medication use. We did not abstract any clinical manifestations because of insufficient clinical data in the RISE-BD records.

\section{Statistical analysis}

Descriptive statistics including mean and standard deviation (SD), and median and interquartile range (IQR), were reported for continuous variables, while frequency and percent were reported for categorical variables to describe BD patients within the RISE registry and those included in studies from endemic regions. Comparisons of the proportion of patients using different medications between men and women in the RISE registry were performed using chi-square tests. A $p$-value of less than 0.05 was considered statistically significant. All data analyses were conducted using SAS 9.4 (SAS institute, Cary, NC), and Stata statistical software version 15 (StataCorp). For privacy protections, we reported no cell sizes $<10$. The Western IRB and UCSF Committee on $\mathrm{Hu}-$ man Research approved this study.

\section{Results}

\section{Characteristics of BD patients in the U.S.}

A total of 1323 subjects with BD from the RISE registry were analyzed. The female to male ratio was $3.8: 1$, with a mean age of $48.7(\mathrm{SD}=16.3)$ years. The majority of patients were white (66.7\%) which is similar to the underlying population of all RISE patients (64.9\%). The median duration of follow-up in the registry was 2.5 (IQR 0.9, 4.4) years (Table 1). Most patients were enrolled in a private health plan $(42.1 \%)$ or Medicare (15.5\%). Osteoporosis (11.7\%), hypertension (8.8\%), and dyslipidemia (4.7\%) were among the most commonly observed comorbid conditions. The mean Deyo-Charlson Index score was 0.55 ( $\mathrm{SD}=1.0) ; 9.3 \%$ of patient had a score equal to or more than 2 .

The distribution of age, sex, and ethnicity of patients with $\mathrm{BD}$ was different compared to the underlying population of patients in the RISE registry (Supplemental
Table 1). The $F$ to $M$ ratio was higher in $\mathrm{BD}$ patients compared to the overall RISE population (3.8:1 vs 2.8:1, $p<0.0001)$. We found a significantly higher proportion of Asian patients with BD compared to the overall RISE population $(2.6 \%$ vs $1.6 \%, p<0.0001)$. In contrast, there was a lower proportion of Black patients (4.9 vs. 7.2, $p<$ 0.0001).

The systemic medications used to manage $\mathrm{BD}$ in the RISE registry are shown in Table 2 . The most frequently used medications included glucocorticoids (67.6\%) and colchicine (55.0\%). Infliximab and adalimumab were the most commonly used biologics $(14.5 \%$ and $14.1 \%$, respectively); $3.2 \%$ of patients used apremilast. There were no significant differences in the proportion of patients using each class of medication between men and women, Fig. 1.

We found that $78(5.9 \%)$ of BD patients were using at least one of the anticoagulants. The most frequently used anticoagulant was warfarin followed by Rivaroxaban in $3.0 \%$ and $2.0 \%$ of $\mathrm{BD}$ patients, respectively.

\section{Comparison of BD patients between the U.S. and studies from endemic areas}

Sociodemographic and medication information extracted from four published studies that met the inclusion criteria described above: Egypt (Egyptian College of Rheumatology (ECR) Registry) $(N=1526)$, Turkey $(N=$ 682), Iran $(N=163)$, and Japan $(N=135)$ [7, 11-13]. Data from the U.S. and BD cohorts from endemic regions is shown in Table 3. In general, the RISE registry had more women with BD compared to all studies from endemic regions $(79.3 \%$ in RISE vs. $27.8 \%$ in the Egyptian cohort, and $16.6 \%$ in the Turkish cohort, $38.7 \%$ in the Iranian cohort, and $57.8 \%$ in the Japanese cohort) and patients were older (mean age (SD); 48.7 (16.3) in RISE vs. 35.7 (9.84) in ECR and 33.9 (9.9) in Turkish). There were differences in medication use, with methotrexate and TNFi used more commonly used in RISE patients $(21.8 \%$ and $29.4 \%)$ compared to the ECR $(7.2 \%$ and $8.3 \%)$. Colchicine and cyclosporine were more commonly used in other cohorts compared to RISE patients. Fewer patients in RISE were treated with glucocorticoids than in Egypt (67.6\% vs 90.2\%), although we did not observe these differences in the Iranian cohort (67.5\%).

\section{Discussion}

Although Behçet's disease is rare in North America, this report from the RISE registry includes the largest dataset of U.S. patients with BD to date. Among $1323 \mathrm{BD}$ patients seen by U.S. rheumatologists, BD patients were more likely to be female, thus confirming previous reports from smaller studies [2, 4-6]. Nearly one third of $\mathrm{BD}$ patients in the RISE registry used TNFi, which is higher than has been previously reported and 
Table 1 Characteristics of patients with Behçet's disease in the RISE registry

\begin{tabular}{|c|c|c|}
\hline \multicolumn{2}{|l|}{ Characteristics } & \multirow{2}{*}{$\frac{\text { Total patients }(N=1323)}{48.7(16.3)}$} \\
\hline Age, mean (SD) & & \\
\hline Sex (female), $N(\%)$ & & $1049(79.3)$ \\
\hline \multirow[t]{6}{*}{ Race, $N(\%)$} & White & $882(66.7)$ \\
\hline & Hispanic or Latino & $72(5.4)$ \\
\hline & Black or African American & $65(4.9)$ \\
\hline & Asian & $34(2.6)$ \\
\hline & Other $^{a}$ & $106(11.9)$ \\
\hline & Missing & $164(12.4)$ \\
\hline \multirow[t]{5}{*}{ Insurance, $N(\%)$} & Medicare & $205(15.5)$ \\
\hline & Private & $557(42.1)$ \\
\hline & Medicaid & $43(3.2)$ \\
\hline & Other $^{\mathrm{b}}$ & $75(5.7)$ \\
\hline & Missing & $443(33.5)$ \\
\hline \multirow[t]{10}{*}{ U.S. geographic division, $N(\%)$} & East North Central & $22(1.7)$ \\
\hline & West North Central & $153(11.6)$ \\
\hline & Mid-Atlantic & $159(12.0)$ \\
\hline & Mountain & $109(8.2)$ \\
\hline & New England & $396(29.9)$ \\
\hline & Pacific & $116(8.8)$ \\
\hline & South Atlantic & $153(11.6)$ \\
\hline & East South Central & $62(4.7)$ \\
\hline & West South Central & $144(10.9)$ \\
\hline & Missing & $<10$ \\
\hline \multirow[t]{9}{*}{ Comorbidities, N (\%) } & Osteoporosis & $155(11.7)$ \\
\hline & Hypertension & $117(8.8)$ \\
\hline & Hyperlipidemia & $62(4.7)$ \\
\hline & Cerebrovascular accidents /TIA & $51(3.7)$ \\
\hline & Diabetes mellitus & $48(3.6)$ \\
\hline & Charlson comorbidity index score, mean (SD) & $0.55(1.0)$ \\
\hline & Charlson comorbidity index score & \\
\hline & 1 & $339(25.6)$ \\
\hline & $\geq 2$ & $123(9.3)$ \\
\hline \multirow[t]{2}{*}{ Clinical characteristics } & Number of visits in RISE, median (IQR) & $4.5(2.5,8)$ \\
\hline & Duration of follow-up time (years), median (IQR) & $2.5(0.9,4.4)$ \\
\hline
\end{tabular}

RISE Rheumatology Informatics System for Effectiveness, TIA transient ischemic attack, IQR interquartile range ${ }^{a}$ Other race: Not determined OMB race, and American Indian or Alaska, Native Hawaiian

${ }^{\mathrm{b}}$ Other insurance: include Veteran

significantly higher than reported in studies from endemic regions. Consistent with prior reports, BD has a higher prevalence among Asian patients, and it has rarely been reported in the Black population $[1,14]$. One potential explanation is the high prevalence of HLAB*51 among Asians, an allele that has also been implicated in BD [14].

The female predilection (79.3\%) in the current study is consistent with previous reports of U.S.-based studies
$(64-80 \%)[5,7,13,15]$. The sex distribution found in RISE data is in contrast to reports from Eastern and Middle East countries that demonstrate a male predominance [16]. The reasons underlying sex distribution differences remain largely unknown but are likely multifactorial. This may be attributed in part to a possible cultural reluctance among women from Eastern countries to visit a physician for genital ulcers leading to underestimation of women with $\mathrm{BD}$, which is supported 
Table 2 Medications administered to patients with Behçet's disease in the RISE registry

\begin{tabular}{|c|c|c|}
\hline Medications & & Total patients $(N=1323)$ \\
\hline No therapy recorded & & $111(8.4)$ \\
\hline Colchicine & & $728(55.0)$ \\
\hline Dapsone & & $62(4.7)$ \\
\hline Glucocorticoids & Any prednisone or equivalent ${ }^{a}$ & $895(67.6)$ \\
\hline csDMARDs & Azathioprine & $418(31.6)$ \\
\hline & Methotrexate & $288(21.8)$ \\
\hline & Hydroxychloroquine & $117(8.8)$ \\
\hline & Sulfasalazine & $53(4.0)$ \\
\hline & Mycophenolate & $31(2.3)$ \\
\hline & Leflunomide & $26(2.0)$ \\
\hline & Cyclosporine & $23(1.7)$ \\
\hline & Tacrolimus & $11(0.83)$ \\
\hline & Cyclophosphamide & $<10$ \\
\hline & Minocycline & $<10$ \\
\hline Biologics-TNFi & Infliximab & $192(14.5)$ \\
\hline & Adalimumab & $187(14.1)$ \\
\hline & Etanercept & $92(6.9)$ \\
\hline & Certolizumab & $30(2.3)$ \\
\hline & Golimumab & $20(1.5)$ \\
\hline Biologics-non-TNFi ${ }^{b}$ & & $59(4.5)$ \\
\hline Targeted small molecules & Tofacitinib & $11(0.80)$ \\
\hline & Baricitinib & $<10$ \\
\hline & Apremilast & $42(3.2)$ \\
\hline Anticoagulants & Warfarin & $39(2.9)$ \\
\hline & Rivaroxaban & $27(2.0)$ \\
\hline & Apixaban & $15(1.1)$ \\
\hline & Enoxaparin & $11(0.8)$ \\
\hline & Dabigatran & $<10$ \\
\hline & Edoxaban & $0(0.0)$ \\
\hline
\end{tabular}

RISE Rheumatology Informatics System for Effectiveness, csDMARDs conventional disease modifying anti-rheumatic drugs, TNFi tumor necrosis factor inhibitors For privacy protection, we reported no cell sizes $<10$

aprednisone or equivalent included prednisone and other oral and intravenous steroids

${ }^{b}$ Biologics-non-TNFi include rituximab, abatacept, tocilizumab, ustekinumab, anakinra, and secukinumab

by the lower prevalence of genital ulcers reported in these countries [17]. However, it is unclear whether the observed difference in sex predilection represents women using more healthcare in the U.S. [18] compared to other countries or a true difference in the epidemiology of BD due to environmental or geographic factors.

Prior studies have also shown differences in the prevalence of specific BD clinical manifestations between the sexes $[19,20]$. We attempted to extract information about clinical manifestations of BD from RISE data, but we found that they were severely under coded in the EHR by rheumatologists, including a low number of ICD codes for oral and genital ulcers and chronic uveitis even among patients with multiple codes for BD (data not shown). Other studies have also noted underestimation of specific clinical phenotypes using EHR data [21], including in other rheumatic conditions [22]. Prior BD studies identified manifestations using medical record review [2, 13]; however, within the RISE registry, it is not possible to perform systematic chart reviews for patients at this time. In the future, a combination of text mining and manual review of clinical text to extract information may allow for more detailed identification of specific disease manifestations in the RISE registry [23, 24]. In addition, the fact that BD patients may seek care from clinicians across many different specialties, including neurology, dermatology, ophthalmology, and rheumatology makes it challenging to gain a complete 


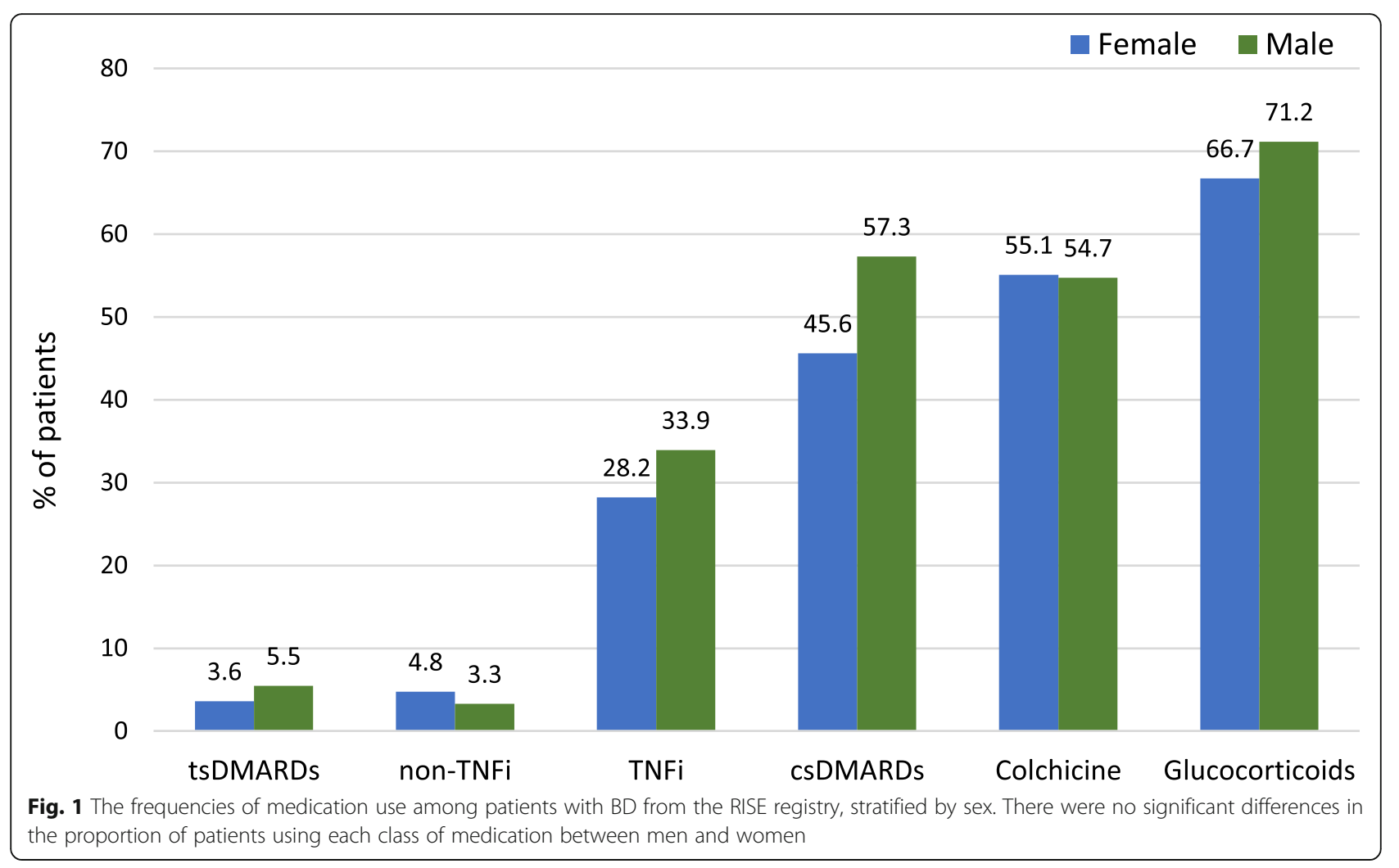

view regarding clinical manifestations from single specialty EHR records. Research into different presentation of $\mathrm{BD}$ in nonendemic areas may provide new clues to the pathogenesis of this condition.

Given the heterogeneity of BD, treatment approaches are highly variable and based on the severity of organ involvement and patient preferences [25]. An obstacle for treating patients with $\mathrm{BD}$ is the lack of the Food and Drug Administration (FDA) approved therapies; aside from apremilast (July 19, 2019), all other therapeutic options are prescribed off-label. The systemic medications used to manage Behçet's disease largely consist of glucocorticoids and colchicine. In the RISE registry, a large proportion of patients $(67.6 \%)$ were treated with systemic glucocorticoids, as noted in other U.S. cohorts (34.0-82.1\%) [5, 7, 15]. Similar to previous reports, about one third of patients were treated with newer therapies including biologics such as TNFi drugs [5, 7, 15]. Also, non-TNFi drugs such secukinumab and ustekinumab were used by some rheumatologists; data on these agents are limited [26, 27]. The present study is also the first real-world setting reporting the use of apremilast in the treatment of BD patients (3.2\%), even the study period was prior to the FDA approval of apremilast for BD mouth ulcers. To date, apremilast, a phosphodiesterase 4 (PDE4) inhibitor, is the only drug currently approved by the U.S. FDA for the treatment of oral ulcers associated with BD [28].
The difference in use of biologic medications between the U.S., and published data from endemic regions may be driven by many factors. First U.S. patients seen by rheumatologists may have more joint complaints, as has been described in other studies [7, 13], and biologics would be well-suited for these symptoms. Second, insurance systems are likely different between the U.S. and Eastern countries, which may make biologic medications more accessible in the U.S. Rheumatologists preferred the choice of anti-TNFi therapy over conventional DMARDs for BD when cost and prior authorization issue were not a concern [29]. Third, U.S. primary care physicians may not be as familiar with this rare disease; thus, only the most complicated patients may be diagnosed and treated by rheumatologists. The magnitude of the regional impact on treatment differences remains difficult to assess, mainly because we were unable to explore the clinical manifestation of BD in this study.

There are several strengths of this study. We report on the largest collection of adult BD patients in the U.S. using a nationwide registry. These data provide realworld evidence of disease management rather than being limited to single, academic centers. However, our study has several potential limitations. First, diagnosis codes used in the identification of BD are good indicators but do not guarantee the presence of disease, although Lenert et al. [9] examined the validity of ICD codes to identify $\mathrm{BD}$ patients and found that the positive 
Table 3 Summary of the sociodemographic characteristics and treatments administered to patients with Behçet's disease in the RISE (U.S.) registry and studies from endemic regions

\begin{tabular}{|c|c|c|c|c|c|c|}
\hline Characteristics & & $\begin{array}{l}\text { Patients with BD } \\
\text { in U.S. (RISE) }(N= \\
1323)\end{array}$ & $\begin{array}{l}\text { Patients with BD in } \\
\text { Egypt (ECR) [11] }(N \\
=1526)\end{array}$ & $\begin{array}{l}\text { Patients with BD } \\
\text { in Turkey [12] }(N \\
=682)\end{array}$ & $\begin{array}{l}\text { Patients with } \\
\text { BD in Iran [7] ( } N \\
=163)\end{array}$ & $\begin{array}{l}\text { Patients with BD } \\
\text { in Japan [13] }(N \\
=135)\end{array}$ \\
\hline \multirow[t]{2}{*}{ Sociodemographic } & Age, mean (SD) & $48.7(16.3)$ & $35.7(9.84)$ & $33.0(9.9)$ & NR & NR \\
\hline & Female, N (\%) & $1049(79.3)$ & $424(27.8)$ & $113(16.6)$ & $63(38.7)$ & $78(57.8)$ \\
\hline \multirow[t]{22}{*}{ Medications } & Colchicine, $N(\%)$ & $728(55.0)$ & $611(82.7)$ & $599(87.8)$ & $108(66.3)$ & $90(66.7)$ \\
\hline & Dapsone, N (\%) & $62(4.7)$ & $N R$ & NR & NR & $0(0.0)$ \\
\hline & $\begin{array}{l}\text { Glucocorticoids, N } \\
(\%)\end{array}$ & $895(67.6)$ & $947(90.2)$ & $384(56.3)$ & $110(67.5)$ & $78(57.8)$ \\
\hline & CDMARDs, $N(\%)$ & & & & & $1(0.70)$ \\
\hline & Azathioprine, N (\%) & 418 (31.6) & $474(26.7)$ & $347(50.8)$ & $48(29.4)$ & $17(12.6)$ \\
\hline & Methotrexate, N (\%) & $288(21.8)$ & $67(7.2)$ & $14(2.1)$ & $51(31.3)$ & $9(6.7)$ \\
\hline & $\begin{array}{l}\text { Hydroxychloroquine, } \\
N(\%)\end{array}$ & $117(8.8)$ & NR & NR & $N R$ & NR \\
\hline & Sulfasalazine, $N(\%)$ & $53(4.0)$ & $N R$ & $51(7.5)$ & $3(5.4)$ & $31(23.0)$ \\
\hline & $\begin{array}{l}\text { Mycophenolate, N } \\
(\%)\end{array}$ & $31(2.3)$ & $N R$ & NR & $0(0.0)$ & $0(0.0)$ \\
\hline & Leflunomide & $26(1.9)$ & $N R$ & $N R$ & $N R$ & NR \\
\hline & Cyclosporine, $N(\%)$ & $23(1.5)$ & $282(26.7)$ & $93(13.6)$ & $13(8.0)$ & $14(10.4)$ \\
\hline & $\begin{array}{l}\text { Cyclophosphamide, } \\
N(\%)\end{array}$ & $<10$ & $208(20.1)$ & $39(5.7)$ & 39 (23.9) & $0(0.0)$ \\
\hline & Minocycline, N (\%) & $<10$ & $N R$ & $N R$ & NR & NR \\
\hline & Tacrolimus, N (\%) & $11(0.83)$ & $N R$ & $N R$ & NR & $N R$ \\
\hline & $\begin{array}{l}\text { Biologics-TNFi, } N \\
(\%)\end{array}$ & $389(29.4)$ & $83(8.3)$ & $N R$ & $1(0.60)$ & NR \\
\hline & Infliximab, N (\%) & $192(14.5)$ & $N R$ & $4(0.6)$ & NR & NR \\
\hline & Adalimumab, N (\%) & $187(14.1)$ & $N R$ & NR & NR & $10(7.4)$ \\
\hline & Etanercept, $N(\%)$ & $92(6.9)$ & NR & NR & NR & $1(0.70)$ \\
\hline & Golimumab, N (\%) & $20(1.5)$ & $N R$ & NR & NR & $0(0.0)$ \\
\hline & Certolizumab, N (\%) & $30(2.3)$ & $N R$ & NR & NR & $N R$ \\
\hline & $\begin{array}{l}\text { Biologics-non- } \\
\text { TNFi' }{ }^{a}, N(\%)\end{array}$ & $59(4.5)$ & $N R$ & NR & $N R$ & NR \\
\hline & tsDMARDs & $53(4.0)$ & NR & NR & NR & NR \\
\hline
\end{tabular}

RISE Rheumatology Informatics System for Effectiveness, ECR Egyptian College of Rheumatology, csDMARDs conventional disease modifying anti-rheumatic drugs, TNFi tumor necrosis factor inhibitors, NR non recorded

${ }^{a}$ Biologics-non-TNFi include rituximab, abatacept, tocilizumab, ustekinumab, and secukinumab

predictive value was excellent (> 99\%). Second, as discussed above, we did not have access to information on BD clinical manifestations. Third, one potential limitation of the data related to anticoagulants is the multiple possible indications for their use. We cannot be certain of the indication of anticoagulants used among included patients as these drugs are commonly prescribed in the management of non-thrombotic conditions, e.g., primary prevention of stroke in atrial fibrillation. Fourth, a direct comparison of RISE-BD vs non-RISE studies was complicated by differences in the methods of studies performed and the availability of data collected. Other limitations in the comparison could be due to differences in sample sizes. Future work should explore whether differences in clinical manifestations can explain the differences in treatment strategies.

\section{Conclusion}

In conclusion, the RISE registry captured data from 1323 patients with BD distributed across all races/ethnicities and geographic regions of the U.S. The current study represents the largest dataset of U.S. BD patients reported to date. We confirmed the female predominance in the U.S. and found that a substantial proportion of $\mathrm{BD}$ patients were taking a biologic medication. In comparison to patients in endemic regions, U.S. BD patients were older and received more biological medications, which raises the possibility that there are a variety 
of epidemiologic and clinical differences in disease between patients in the U.S. and those from endemic areas. Future studies examining clinical manifestations among large numbers of U.S. BD patients are needed.

\begin{abstract}
Abbreviations
BD: Behçet's disease; CCl: Charlson Comorbidity Index; CSDMARDs: Conventional synthetic DMARDs; ECR: Egyptian College of Rheumatology; EHR: Electronic health record; ICD-9-CM: International Classification of Diseases, Ninth Revision, Clinical Modification; ICD-10CM: International Classification of Diseases, Tenth Revision, Clinical Modification; PDE4: Phosphodiesterase 4 inhibitor; RISE: Rheumatology Informatics System for Effectiveness; TNF: Tumor necrosis factor; tsDMARDs: Targeted synthetic DMARDs; U.S.: United States
\end{abstract}

\section{Supplementary Information}

The online version contains supplementary material available at https://doi. org/10.1186/s13075-021-02615-7.

Additional file 1:. Supplementary Table 1. Characteristics of patients with $\mathrm{BD}$ compared with all patients in the RISE registry.

\section{Acknowledgements}

Not applicable.

\section{Authors' contributions}

$\mathrm{NH}, J Y$, and GS designed the work. $\mathrm{NH}$ performed the statistical analysis. $\mathrm{NH}$, $J \mathrm{~L}, \mathrm{ME}$, and JK extracted and interpreted the data. $\mathrm{NH}$ and GS drafted the paper. $\mathrm{NH}, \mathrm{ZI}, \mathrm{CA}, \mathrm{MAG}, \mathrm{JY}$, and GS edited and reviewed the paper. The authors read and approved the final manuscript.

\section{Funding}

Drs. Yazdany and Schmajuk are supported by the Russell/Engleman Medical Research Center for Arthritis. Dr. Yazdany is supported by NIAMS P30 AR070155 and K24AR074534. The data presented here was supported by the American College of Rheumatology's RISE Registry. However, the views expressed represent those of the author(s) and do not necessarily represent the views of the American College of Rheumatology. This study protocol was prepared by and the data analysis was executed by the RISE data analytic center at UCSF.

\section{Availability of data and materials}

The American College of Rheumatology (ACR) owns the data in the RISE registry, and UCSF, as a Data Analytic Center for the ACR, has access to the data for specific research projects, including this one, but is contractually obligated to not share this data, even in a de-identified state.

\section{Declarations}

Ethics approval and consent to participate

The Western IRB and UCSF Committee on Human Research approved this study.

\section{Consent for publication}

Not applicable.

\section{Competing interests}

The authors declare that they have no competing interests.

\section{Author details}

'Division of Rheumatology, Department of Medicine, University of California San Francisco, San Francisco, CA, USA. ${ }^{2}$ Philip R. Lee Institute for Health Policy Research, San Francisco, USA. ${ }^{3}$ San Francisco Veterans Affairs Medical Center, 4150 Clement St 111R, San Francisco, CA 94121, USA.
Received: 31 March 2021 Accepted: 23 August 2021

Published online: 30 August 2021

\section{References}

1. Leonardo NM, McNeil J. Behcet's disease: is there geographical variation? A review far from the Silk Road. Int J Rheumatol. 2015:2015:1-7.

2. Calamia KT, Wilson FC, Icen M, Crowson CS, Gabriel SE, Kremers HM. Epidemiology and clinical characteristics of Behçet's disease in the US: a population-based study. Arthritis Rheum. 2009;61(5):600-4. https://doi.org/1 0.1002 /art.24423

3. Yazici $H$, Tüzün $Y$, Pazarli $H$, Yurdakul S, Ozyazgan $Y$, Ozdoğan $H$, et al. Influence of age of onset and patient's sex on the prevalence and severity of manifestations of Behçet's syndrome. Ann Rheum Dis. 1984:43(6):783-9. https://doi.org/10.1136/ard.43.6.783

4. Davari P, Rogers RS, Chan B, Nagler TH, Fazel N. Clinical features of Behçet's disease: a retrospective chart review of 26 patients. J Dermatol Treat. 2016; 27(1):70-4. https://doi.org/10.3109/09546634.2015.1054781.

5. Sibley C, Yazici Y, Tascilar K, Khan N, Bata Y, Yazici H, et al. Behçet syndrome manifestations and activity in the United States versus Turkey - a crosssectional cohort comparison. J Rheumatol. 2014;41(7):1379-84. https://doi. org/10.3899/jrheum.131227.

6. Muruganandam M, Rolle NA, Sibbitt WL, Cook GB, Emil NS, Fangtham M, et al. Characteristics of Behcet's disease in the American Southwest. Semin Arthritis Rheum. 2019;49(2):296-302. https://doi.org/10.1016/j.semarthrit.201 9.03.003.

7. Shahram F, Mæhlen MT, Akhlaghi M, Davatchi F, Liao YJ, Weyand CM. Geographical variations in ocular and extra-ocular manifestations in Behçet's disease. Eur J Rheumatol. 2019;6(4):199-206. https://doi.org/10.5152/ eurjrheum.2019.18215.

8. Yazdany J, Bansback N, Clowse M, Collier D, Law K, Liao KP, et al. Rheumatology informatics system for effectiveness: a national informaticsenabled registry for quality improvement. Arthritis Care Res. 2016;68(12): 1866-73. https://doi.org/10.1002/acr.23089.

9. Lenert A, Russell MJ, Segerstrom S, Kim S. Accuracy of US administrative claims codes for the diagnosis of autoinflammatory syndromes. J Clin Rheumatol. 2020.

10. Deyo RA, Cherkin DC, Ciol MA. Adapting a clinical comorbidity index for use with ICD-9-CM administrative databases. J Clin Epidemiol. 1992;45(6):613-9. https://doi.org/10.1016/0895-4356(92)90133-8.

11. Gheita TA, El-Latif EA, El-Gazzar II, Samy N, Hammam N, Abdel Noor RA, et al. Behçet's disease in Egypt: a multicenter nationwide study on 1526 adult patients and review of the literature. Clin Rheumatol. 2019;38(9):256575. https://doi.org/10.1007/s10067-019-04570-w.

12. Yilmaz S, Karadag O, Yazisiz V, Altun B, Gezer M, Karaman M, et al. Systemic involvements and preferred treatments in a large cohort of Behçet's disease. Rheumatol Int. 2013;33(12):3025-30. https://doi.org/10.1007/s00296-013-283 $0-0$

13. Kobayashi T, Kishimoto M, Swearingen CJ, Filopoulos MT, Ohara Y, Tokuda $Y$, et al. Differences in clinical manifestations, treatment, and concordance rates with two major sets of criteria for Behçet's syndrome for patients in the US and Japan: data from a large, three-center cohort study. Mod Rheumatol. 2013;23(3):547-53. https://doi.org/10.3109/s10165-012-0696-8.

14. Mahmoudi M, Aslani S, Meguro A, Akhtari M, Fatahi Y, Mizuki N, et al. A comprehensive overview on the genetics of Behçet's disease. Int Rev Immunol. 2020:1-64. https://doi.org/10.1080/08830185.2020.1851372.

15. Kilian NC, Sawalha AH. Behçet's disease in the United States: a single center descriptive and comparative study. Eur J Rheumatol. 2017:4(4):239-44. https://doi.org/10.5152/eurjrheum.2017.17112

16. Davatchi F, Shahram F, Chams-Davatchi C, Sadeghi Abdollahi B, Shams H, Nadji A, et al. Behcet's disease: is there a gender influence on clinical manifestations? Int J Rheum Dis. 2012;15(3):306-14. https://doi.org/10.1111/ j.1756-185X.2011.01696.X

17. Davatchi F, Shahram F, Chams-Davatchi C, Shams H, Nadji A, Akhlaghi M, et al. Behcet's disease: from East to West. Clin Rheumatol. 2010:29(8):823-33. https://doi.org/10.1007/s10067-010-1430-6.

18. Mahr A, Belarbi L, Wechsler B, Jeanneret $D$, Dhote $R$, Fain $O$, et al. Population-based prevalence study of Behcet's disease: differences by ethnic origin and low variation by age at immigration. Arthritis Rheum. 2008;58(12):3951-9. https://doi.org/10.1002/art.24149.

19. Ishido T, Horita N, Takeuchi M, Kawagoe T, Shibuya E, Yamane T, et al. Clinical manifestations of Behçet's disease depending on sex and age: 
results from Japanese nationwide registration. Rheumatology. 2017;56(11): 1918-27. https://doi.org/10.1093/rheumatology/kex285.

20. Bonitsis NG, Luong Nguyen LB, LaValley MP, Papoutsis N, Altenburg A, Kotter I, et al. Gender-specific differences in Adamantiades-Behcet's disease manifestations: an analysis of the German registry and meta-analysis of data from the literature. Rheumatol Oxf Engl. 2015;54(1):121-33. https://doi.org/1 0.1093/rheumatology/keu247.

21. Pathak J, Kho AN, Denny JC. Electronic health records-driven phenotyping: challenges, recent advances, and perspectives. J Am Med Inform Assoc JAMIA. 2013;20(e2):e206-11. https://doi.org/10.1136/amiajnl-2013-002428.

22. Hammam N, Evans M, Morgan E, Reimold A, Anastasiou C, Kay JL, et al. Treatment of sarcoidosis in U.S. rheumatology practices: data from ACR's Rheumatology Informatics System for Effectiveness (RISE) Registry. Arthritis Care Res. 2020. https://doi.org/10.1002/acr.24496.

23. Ananthakrishnan AN, Cai T, Savova G, Cheng S-C, Chen P, Perez RG, et al. Improving case definition of Crohn's disease and ulcerative colitis in electronic medical records using natural language processing: a novel informatics approach. Inflamm Bowel Dis. 2013;19(7):1411-20. https://doi. org/10.1097/MIB.0b013e31828133fd.

24. Jamian L, Wheless L, Crofford LJ, Barnado A. Rule-based and machine learning algorithms identify patients with systemic sclerosis accurately in the electronic health record. Arthritis Res Ther. 2019;21(1):305. https://doi. org/10.1186/s13075-019-2092-7.

25. Hatemi G, Christensen R, Bang D, Bodaghi B, Celik AF, Fortune F, et al. 2018 Update of the EULAR recommendations for the management of Behçet's syndrome. Ann Rheum Dis. 2018;77(6):808-18. https://doi.org/10.1136/a nnrheumdis-2018-213225.

26. Di Scala G, Bettiol A, Cojan RD, Finocchi M, Silvestri E, Emmi G. Efficacy of the anti-IL 17 secukinumab in refractory Behçet's syndrome: a preliminary study. J Autoimmun. 2019;97:108-13. https://doi.org/10.1016/j.jaut.2018.09. 002.

27. Mirouse A, Barete $S$, Desbois A-C, Comarmond C, Sène $D$, Domont $F$, et al. Long-term outcome of ustekinumab therapy for Behçet's disease. Arthritis Rheumatol Hoboken NJ. 2019;71(10):1727-32. https://doi.org/10.1002/art.4 0912.

28. Celgene Corporation. FDA approves OTEZLA ${ }^{\oplus}$ (apremilast) for the treatment of oral ulcers associated with Behçet's disease. 2019. https:/ir.celgene.com/ press-releases-archive/press-release-details/2019/FDA-Approves-OTEZLA-a premilast-for-the-Treatment-of-Oral-Ulcers-Associated-with-Behets-Disease/ defaultaspx. Accessed 19 Oct 2020.

29. Palestine AG, Kolfenbach JR, Ozzello DJ. Rheumatologists and ophthalmologists differ in treatment decisions for ocular Behçet disease. J Clin Rheumatol Pract Rep Rheum Musculoskelet Dis. 2016;22:316-9.

\section{Publisher's Note}

Springer Nature remains neutral with regard to jurisdictional claims in published maps and institutional affiliations.

Ready to submit your research? Choose BMC and benefit from:

- fast, convenient online submission

- thorough peer review by experienced researchers in your field

- rapid publication on acceptance

- support for research data, including large and complex data types

- gold Open Access which fosters wider collaboration and increased citations

- maximum visibility for your research: over $100 \mathrm{M}$ website views per year

At $\mathrm{BMC}$, research is always in progress.

Learn more biomedcentral.com/submissions 